Available online at: http://ejournal-balitbang.kkp.go.id/index.php/iaj

\title{
STUDY ON SURVIVABILITY OF NEWLY HATCHED LARVAE OF TWO SPECIES OF PEPPERMINT SHRIMP FED WITH DIFFERENT COMBINATIONS AND DENSITIES OF LIVE FOODS
}

\author{
Indra Pratama\# and Hatim Albasri \\ Research Center for Fisheries \\ Gedung BRSDMKP II, JI. Pasir Putih II, Ancol Timur 14430, Jakarta \\ (Received 6 February 2018; Final revised 27 April 2018; Accepted 27 April 2018)
}

\begin{abstract}
This study was aimed to evaluate different types and combinations of live foods in relation to the survivability of newly hatched Lysmata vittata and Lysmata intermedia larvae. The experiment consisted of three trials (different species, combinations, and densities of live foods) arranged in a completely randomized design. The first and second trials were subjected to $L$. vittata with three treatments for each trial $(1 A, 1 B, 1 C$ for trial-1; 1D, 1E, 1F for trial-2). The third trial consisted of two treatments (2A and $2 B$ ) tested on $\mathrm{L}$. intermedia. Each treatment had three replicates. The results showed that the survival rates were low in all treatments. However, each treatment showed a significant effect $(P<0.05)$ on the average survival rate of $L$. vittata and L. intermedia larvae. In the first trial, treatment $1 \mathrm{C}$ was the only one that had survived larvae after day 35 with $4.44 \%$ of final average survival rate (FASR). Four of the larvae reached the post-larval stage. In the second trial, treatment $1 \mathrm{~F}$ showed a better condition than the other treatments with $5.56 \%$ FASR. Nevertheless, no larvae in the second trial had transformed to post-larval stage before the experiment ended at day 46. In the third trial, no larvae survived to reach the post-larval stage. In spite of this, treatment $2 \mathrm{~B}$ had better daily average survival rate (DASR) than treatment $2 \mathrm{~A}$. This research concludes that the use of copepods as live food at an early larval stage and Artemia at a later stage is relatively more effective to improve the survival rate of peppermint shrimp larvae.
\end{abstract}

KEYWORDS: larvae; live foods; Lysmata vittata; Lysmata intermedia; survivability

\section{INTRODUCTION}

The peppermint shrimp is one of several groups of marine ornamental shrimps from the genus Lysmata that are highly favoured by marine ornamental fish enthusiasts. Unfortunately, their availability on the market depends mostly on wild stocks. Thus, the shrimps have suffered high exploitation which will render its future sustainability uncertain (Calado, 2008; Cato \& Brown, 2008). The efforts to successfully produce the shrimps in a culture environment to meet the market demands both in number and continuity have been generally slow.

Recently, through a series of aquaculture application helped by science and technology, some species

\# Correspondence: Research Center for Fisheries. Gedung BRSDMKP II, JI. Pasir Putih II, Ancol Timur 14430, Jakarta utara, Indonesia

Phone: + 622164700928

E-mail: indrapratama@ kkp.go.id of marine ornamental shrimp are in a great progress in producing commercially cultured marine ornamental shrimps, for example, skunk cleaner shrimp Lysmata amboinensis, fire shrimp L. debelius, and peppermint shrimp L. seticaudata (Palmtag \& Holt, 2001; Rocha, 2007; Calado, 2008). However, it is still necessary to explore and optimize the existing techniques as well as potential future practices and methods in order to improve the quality, quantity, and diversity in the commercial aquaculture of marine ornamental shrimp (Holt, 2003; Rocha, 2007; Calado, 2008). In fact, there are some other species of marine ornamental shrimp that are not quite well known recently but have a high potential for future market, for example, peppermint shrimp L. vittata and $L$. intermedia. These two species of marine ornamental shrimp are deemed as the new favorite species among marine ornamental fish enthusiasts. Unfortunately, there was limited information regarding the best possible techniques, methods, and diets in the cul- 
ture technique and survival rate, particularly at larval stage of the shrimp (D'Acoz, 2000; Calado, 2008; Baeza, 2008; Marin et al., 2012; Marine Fish Direct, 2014). A successful aquaculture of marine ornamental shrimp strongly correlates with a reliable production of eggs as well as good development and growth of larvae and juveniles (Holt, 2003). Early life stages, especially larval stage, are a very critical period in the aquaculture of marine ornamental shrimp. At this stage, highquality foods are essential to support an optimum larval development and increase the survival rate (Olivotto et al., 2011; Holt, 2003). Therefore, finding the best types and optimum combinations beyond the existing diets is the most important priorities. For example, despite the facts provided by some studies that young juvenile and adult shrimp from genus Lysmata are considered to be a strict carnivorous species (Le Vay et al., 2001), adding microalgae into their carnivorous diets at larval stage enhanced their larvae survival as a consequences of beneficial effects to their nourishment (Simoes et al., 2002). Many studies such as those conducted by Buskey et al. (1993), Zhang et al. (1998), and Cunha et al. (2008) have confirmed the effective use of one or a combination of microalgae, copepods, rotifers, and Artemia to feed larvae of marine ornamental fish. The aim of this study was to evaluate the survivability of newly hatched $L$. vittata and $L$. intermedia larvae using different types and combination of live foods.

\section{MATERIALS AND METHODS}

\section{Feeding Trial Designs}

The experiment consisted of three trials and was arranged in a complete randomized design. The first and second trial had three different treatments each (1A, 1B, 1C for trial-1; 1D, 1E, 1F for trial-2) and were subjected to L. vittata (Figure 1A). The third trial (trial3 ) consisted of two treatments ( $2 A$ and $2 B$ ) and was tested for L. intermedia (Figure 1B). Each treatment had three replicates. The first trial was carried out from 20 March to 07 May 2014 followed by the second trial from 17 April to 01 June 2014. The third trial was conducted from 08 April to 17 May 2014. The experiments were done in two laboratory rooms (Room 11 and Bld. 170) located at Marine and Aquaculture Research Facilities Unit (MARFU), James Cook University, Australia. The seawater supply was obtained from MARFU water circulation system with salinity maintained at 29-31 ppt.

\section{Research Procedures}

The sources of larvae of peppermint shrimp L. vittata and $\mathrm{L}$. intermedia used in this experiment were obtained from the selected berried female broodstock nurtured in an aquarium at MARFU laboratory. Two weeks after spawning, the selected females were isolated into another container until the eggs hatched. The hatching container was filled with seawater, gently aerated without circulation and filtration. The water temperature was maintained at $27^{\circ} \mathrm{C}-29^{\circ} \mathrm{C}$. After the eggs hatched, the females were placed back to the aquarium.

In each trial, on the first day after hatch (DAH 1) the newly hatched larvae of the two shrimp species were distributed into the treatment media consisting of three $500 \mathrm{~mL}$ beakers in triplicates. Each beaker was filled with seawater, aerated very gently through a glass pipette, and stocked with 30 larvae. The water exchange was done at $100 \%$ every day by gently transferring each survived larva into a new clean beaker filled with fresh seawater by using a modified $1 \mathrm{~mL}$ plastic pipette. The larvae were maintained in an optimum culture environment within the recommended temperature and feeding regime (Zhang et al., 1998; Calado et al., 2008, 2009; Figueiredo \& Narciso, 2006). The temperature was monitored and maintained at $27^{\circ} \mathrm{C}-29^{\circ} \mathrm{C}$ with a heater placed whenever necessary.

The dietary treatments implemented in the first trial were $1 \mathrm{~A}, 1 \mathrm{~B}$, and $1 \mathrm{C}$. Microalgae Isochrysis sp. at a concentration equivalent to 100,000 cells $/ \mathrm{mL}$ was used as treatment $1 \mathrm{~A}$, copepod Parvocalanus crassirostris at a density of 10 ind./mL was used as treatment $1 \mathrm{~B}$, and rotifer Brachionus rotundiformis at a density of $15 \mathrm{ind}$./mL was used as treatment $1 \mathrm{C}$. In trial-2, the dietary treatments implemented were treatments $1 \mathrm{D}, 1 \mathrm{E}$, and $1 \mathrm{~F}$. A combination of rotifer B. rotundiformis at a density of $10 \mathrm{ind} . / \mathrm{mL}$ and microalgae Isochrysis $\mathrm{sp}$. at a concentration equivalent to 50,000 cells $/ \mathrm{mL}$ was used as treatment 1D. A mixed of copepod P. crassirostris at $5 \mathrm{ind} . / \mathrm{mL}$ density and microalgae Isochrysis sp. at a concentration equivalent to 50,000 cells/mL was used as treatment $1 \mathrm{E}$. Newly hatched Artemia nauplii at a density of 10 ind./ $\mathrm{mL}$ was used as treatment $1 \mathrm{~F}$. In the third trial, the treatments implemented were $2 \mathrm{~A}$ and $2 \mathrm{~B}$. A combination of rotifer $B$. rotundiformis at a density of 10 ind./mL and microalgae Isochrysis sp. at a concentration equivalent to 50,000 cells $/ \mathrm{mL}$ was used as treatment 2A. Treatment 2B was divided into two phases, $2 B^{1}$ and $2 B^{2}$. Copepod P. crassirostris at the first two weeks (day 1 to 14 ) at a density of 10 ind./mL was used as treatment $2 \mathrm{~B}^{1}$. After that period, newly hatched Artemia (day 14 to end) at a density of 10 ind./mL was used as treatment $2 \mathrm{~B}^{2}$.

All the microalgae, copepod, rotifer, and Artemia used in these experiments were live foods. The microalgae, copepod, and rotifer were taken from 

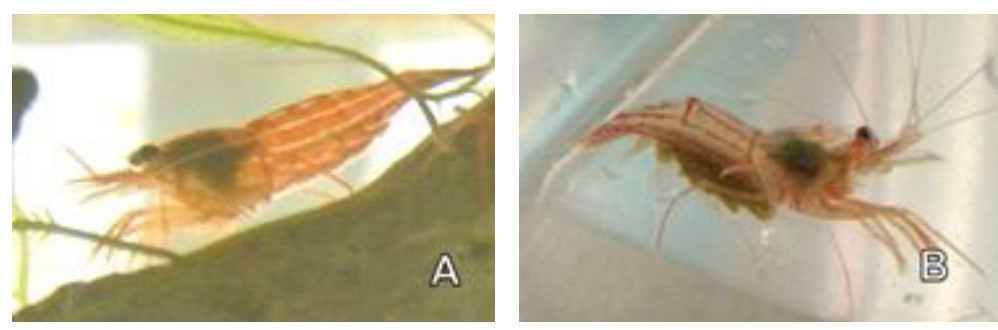

Figure 1. Peppermint shrimp at MARFU, JCU: (A) Lysmata vittata;

(B) Lysmata intermedia, carrying eggs.

cultured tanks while the Artemia were produced daily. Each larva that successfully reached the post-larval stage was transferred into separate tanks and was included in final counting of survivability after the treatments ended. The treatments were considered complete when there were no survived larvae left in each beaker or when the last larvae in a beaker successfully transformed to the post-larval stage. One exception was for trial2, which all the treatments had to be stopped at day after hatch (DAH) 46 due to the limited resources and time.

\section{Calculation and Statistical Analysis}

The daily average survival rates (DASR) and temperature variations were assessed for variance (Levene's test and boxplot) and then analysed with one way ANOVA. Significant differences $(P<0.05)$ in all treatments were identified using the T-method multiple comparison test (Sokal \& Rohlf, 1995). The number of survived larvae at the end of each treatment was counted as the final average survival rate (FASR).

\section{RESULTS AND DISCUSSION}

In trial-1, the overall survival rates were low in all treatments (Figure 2). At day 23, the last larva in treatment $1 \mathrm{~A}$ had died before reaching post-larval stage. The larvae fed with copepod (treatment 1B) had a similar condition where the last larva had died on day 34 without being able to transform to post-larval stage. The larvae fed with rotifer (treatment 1C) had the best performance compared to the other treatments in trial-1 where four larvae survived and successfully reached post-larval stage. This study found that after DAH 5, rotifer was more effective to support larvae survivability than microalgae or copepod (Figure 2). The final average survival rate (FASR) for L. vittata larvae fed with rotifer was $4.44 \%$ Statistically, there were significant differences $(P<0.05)$ in the survival rates between the larvae fed with microalgae, copepod, and rotifer.
Trial-2 has shown similar results compared to the first one where the overall survival rates were low in all treatments (Figure 3). However, in the three treatments of trial-2, some larvae had survived at the end of the experiment (day 46). Despite that, none of the survived larvae had transformed to post-larval stage at the end of the experiment (day 46). In treatment 1D, three larvae were still survived at day 46 with 3.33\%FASR. In treatment $1 \mathrm{E}$, there was only one larva survived at day 46 with $1.11 \%$ FASR. The larvae in treatment $1 \mathrm{~F}$ showed a better condition where five still survived at day 46 with $5.56 \%$ FASR. However, regardless of these seemingly similar situations, there were significant differences $(P<0.05)$ on the survival rates among these three different treatments.

In all treatments of trial-3 with shrimp species $\mathrm{L}$. intermedia, no larvae survived and reached the postlarval stage (Figure 4). In treatment 2A, no larvae survived at day 39 . In treatment $2 B$, at the first two weeks (day 1 to $14 ; 2 \mathrm{~B} 1$ ) and after that (day 14 to end; $2 B 2$ ), the feed was changed with Artemia. The FASR of treatment $2 \mathrm{~B}$ was better than that of treatment $2 \mathrm{~A}$ where one larva had survived in treatment $2 B$ two days after the last larva in treatment 2A died. Despite none of the larvae in both treatments survived or transformed to post-larval stage, the graph (Figure 4) noticeably shows that treatment $2 B$ was better than treatment $2 \mathrm{~A}$ based on the daily average survival rate (DASR). Furthermore, there were significant differences $(P<0.05)$ in the survival rates between larvae fed with treatments $2 \mathrm{~A}$ and $2 \mathrm{~B}$.

The average daily temperature during trial-1 was the highest $\left(28.84 \pm 0.17^{\circ} \mathrm{C}\right)$ and statistically significant $(\mathrm{P}<0.05)$ compared to trial-2 $\left(27.63 \pm 0.16^{\circ} \mathrm{C}\right)$ and trial-3 $\left(27.76 \pm 0.14^{\circ} \mathrm{C}\right.$ ) (Figure 5). Unfortunately, the ambient temperature, as well as the water temperature at the experiment sites, started to decrease by the end of April 2014. In order to maintain water temperature between $28^{\circ} \mathrm{C}-29^{\circ} \mathrm{C}$, a heater was placed in the containers starting on 8 May 2014, which was day 22 of trial-2 and day 31 of trial-3, until the experi- 


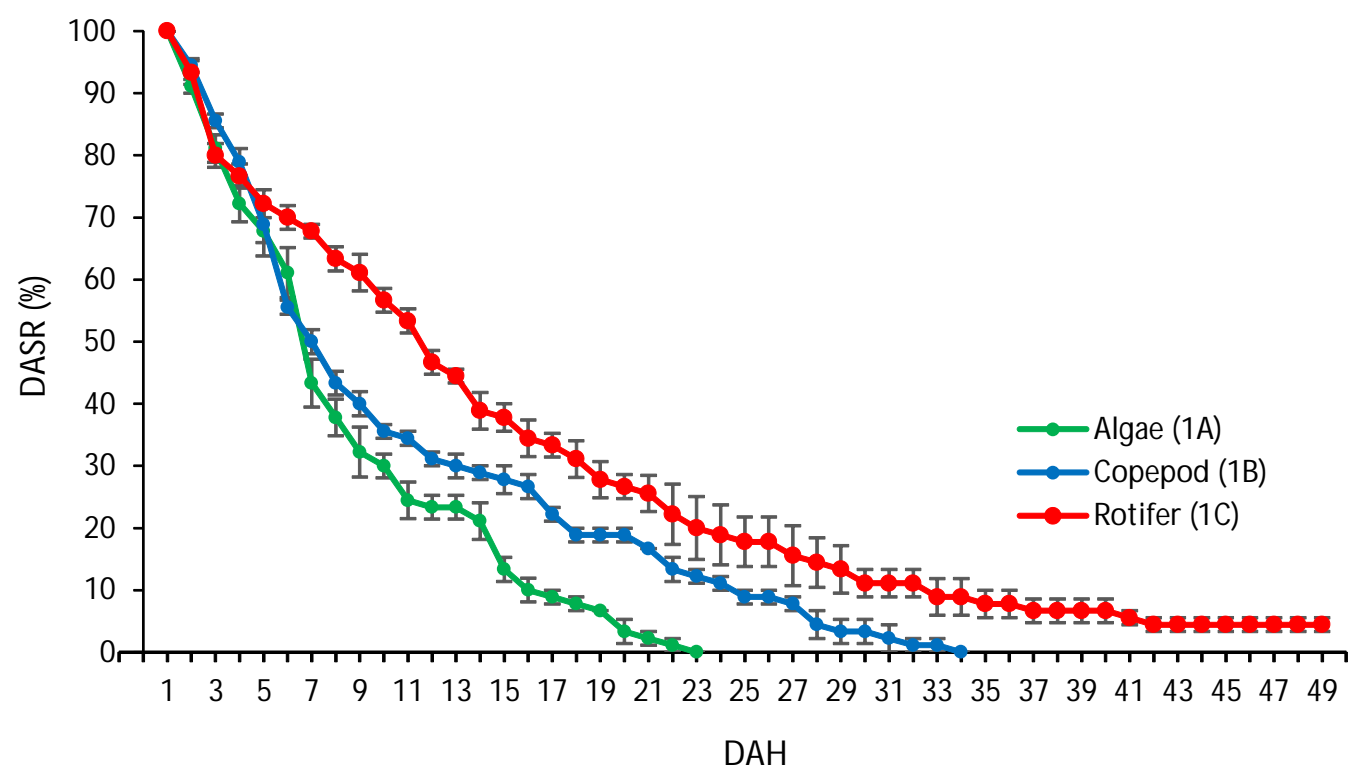

Figure 2. Daily average survival rates ( $\%$ of Lysmata vittata fed with microalgae Isochrysis sp. (treatment 1A), copepod Parvocalanus crassirostris (treatment 1B), and rotifer Brachionus rotundiformis (treatment 1C). Error bars represent $\pm \mathrm{SE}$.

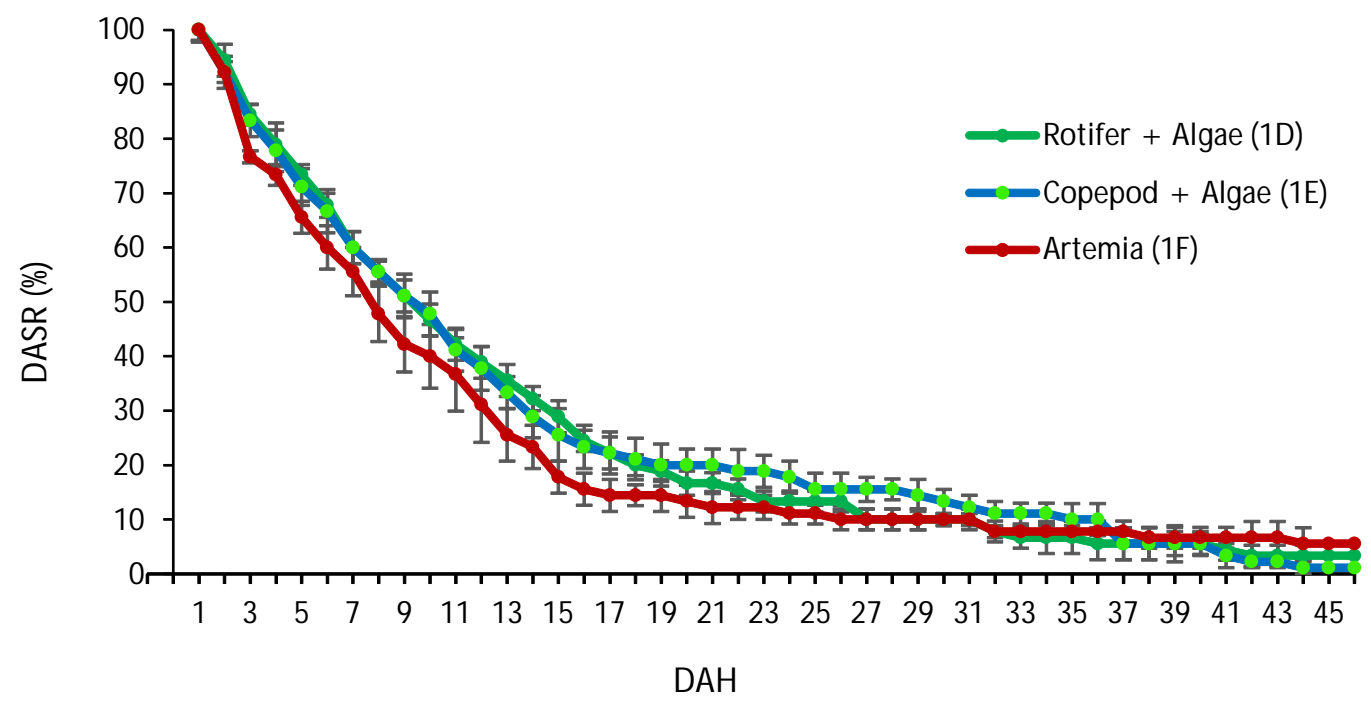

Figure 3. Daily average survival rates (\% of Lysmata vittata fed with combination of rotifer Brachionus rotundiformis and microalgae Isochrysis sp. (treatment 1D), copepod Parvocalanus crassirostris and microalgae Isochrysis sp. (treatment $1 \mathrm{E})$, and Artemia only (treatment $1 F)$. Error bars represent \pm SE.

ments ended. The beakers used in these trials were proportionately placed inside two containers filled with water with the same water height as the beakers. Then the heater was placed between the beakers. Therefore, the ambient temperature data on and after 8 May 2014 were excluded from this report.

Overall, these experiments have resulted in low survival rates in all treatments for $L$. vittata and $L$. intermedia even though the temperature, salinity, and feeding regimes were maintained at recommended ranges. This result might relate to the high initial larval stocking density of 60 ind./L. Cunha et al. (2008) reported that the survival rate of cleaner shrimp, L. amboinensis was significantly higher at the initial stocking density of 10 ind./L rather than at the density of 20 ind./L, with the highest survival rate reach $48 \%$ for larvae fed with rotifer at $35 \mathrm{ind} . / \mathrm{mL}$. However, these findings by Cunha et al. (2008) observed the average 


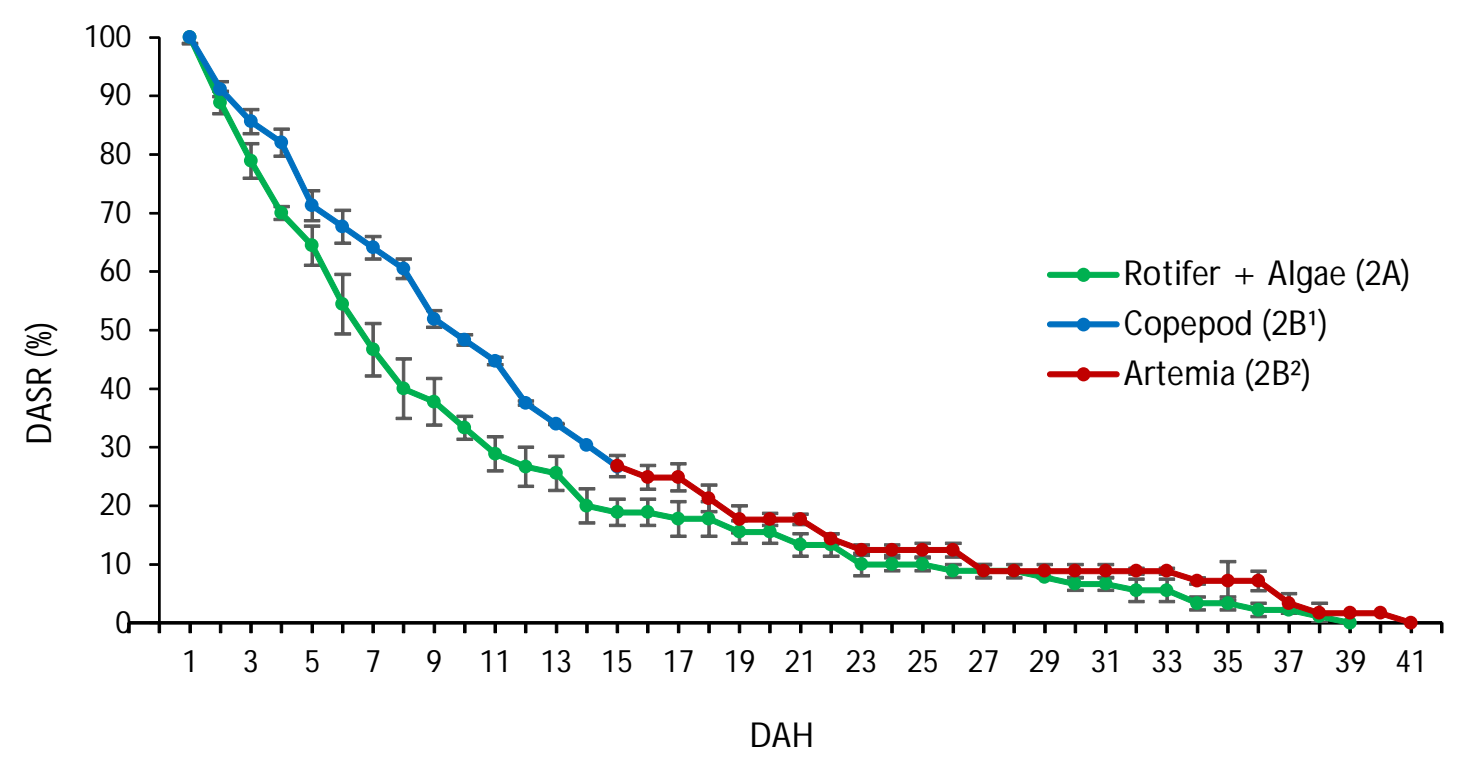

Figure 4. Daily average survival rates (\% of Lysmata intermedia fed with treatment $2 \mathrm{~A}$ which was a combination of rotifer Brachionus rotundiformis and microalgae Isochrysis $\mathrm{sp}$. and larvae fed with treatment $2 \mathrm{~B}$ which these larvae were fed with copepod Parvocalanus crassirostris at the first two weeks (day 1 to $14 ; 2 \mathrm{~B} 1$ ) and then after that change with Artemia nauplii (day 14 to end; 2B2). Error bars represent $\pm \mathrm{SE}$.

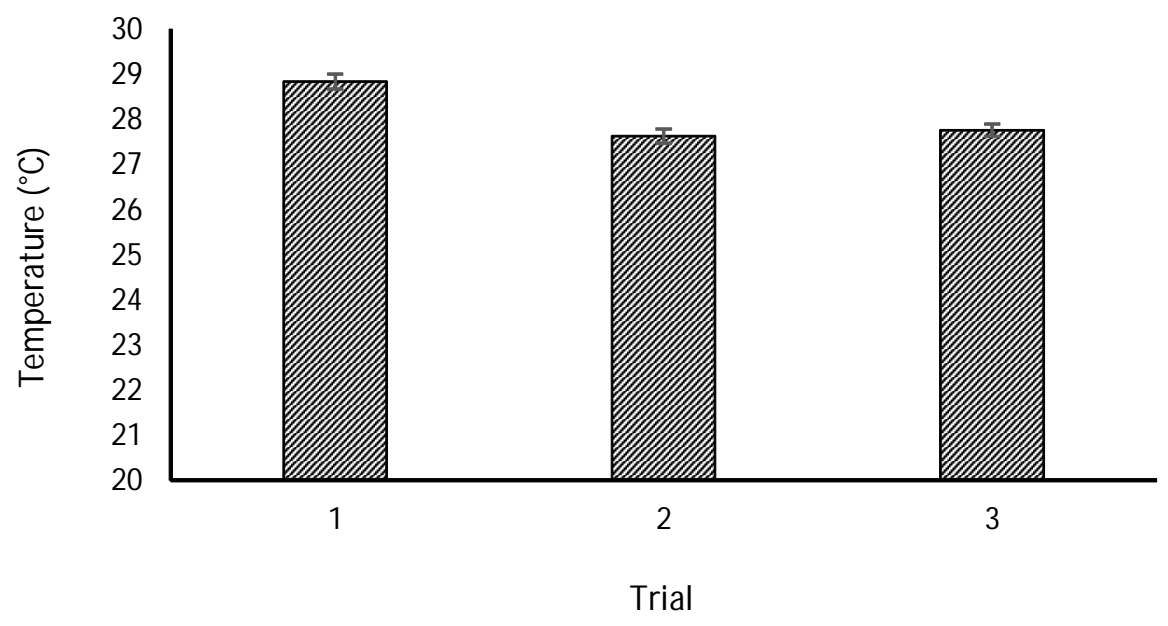

Figure 5. The average daily temperature during the experiments. Error bars represent $\pm \mathrm{SE}$.

survival rate of L. amboinensis fed with different amount of rotifer at three density: 20,35, and 50 ind. $/ \mathrm{mL}$, and only during the first six days of larval stage. Compared to present research results in which larvae of L. vittata stocked at a higher initial density of 60 ind./L and fed with a lower amount of rotifer at 15 ind./mL (treatment 1C), at day- 6 this present experiments achieved an average survival rate of $70.0 \%$ The effects of such densities are most probably related to stress, physical damage, or discomfort as a consequence of higher encounter rates between individuals (Cunha et al., 2008).
All treatments for both $\mathrm{L}$. vittata and $\mathrm{L}$. intermedia larvae had a significant effect $(P<0.05)$ to the DASR of both larvae. Larvae with treatments $1 \mathrm{~A}$ and $1 \mathrm{~B}$ had the lowest survival rates with none of them survived after day 22 for treatment $1 \mathrm{~A}$ and day 33 for treatment 1B. Zhang et al. (1998) reported that the use of microalgae is only effective to support the early stages of larvae and none of them survived to later stages or even transformed to post-larval stages. Nevertheless, using copepod as one of the diets for the early larval stages of Lysmata spp. is highly potential due to a better survival rate compared to using 
microalgae. In spite of this, the treatments with copepod in this experiment have similar results to the treatment with microalgae where they are effective to support the early stages of the larvae. These results probably related to the swimming behavior and body size of calanoid copepod, P. crassirostris used in this experiment. Calanoid copepod is a planktonic species that spends all its life cycle in the water column (Støttrup, 2006). Contrastingly, at the later larval stages, peppermint shrimp Lysmata spp. tend to settle at the bottom rather than swimming (Zhang et al., 1998; D'Acoz, 2000; Marin et al., 2012). In addition, their swimming patterns are significantly different than rotifer. Calanoid copepod has faster swimming speed and higher rates of change of direction and accelerations compared to rotifer. These abilities resulted in higher escape responses of the copepod from predation compared to rotifer (Buskey et al., 1993). Furthermore, the size of calanoid copepod has also influenced the capturing ability of Lysmata spp. Iarvae. Calanoid copepod has a smaller body size compared to rotifer (Buskey et al., 1993). Although larvae of Lysmata spp. are not a visual predator, they primarily rely on their olfactory and mechanical sensory to capture preys (Rhyne $\&$ Lin, 2004). These resulted in lower success rates of L. vittata and $L$. intermedia at a later larval stage to capture copepod compared to rotifer

In contrast, the experiment with treatment $1 \mathrm{C}$ has four survived larvae, all of which successfully reached post-larval stage. The experiment also has shown that the use of rotifer resulted in a better larval survival rate at a later stage compared to microal gae or copepod. Many studies such as Buskey et al. (1993); Zhang et al. (1998); and Cunha et al. (2008), have confirmed the effective use of rotifer to feed larvae of Lysmata spp. A study by Zhang et al. (1998) has al so confirmed that the use of rotifer led to a better survival rate along with a successful transformation of some of the larvae to reach post-larval stage at around day 32-36. Zhang et al. (1998) findings were equivalent to trial-2 which in these three treatments (1D, 1E, and 1F), some larvae still survived until the last day of the experiment (day 46). However, none of the survived larvae in trial-2 were transformed to post-larval stage until the end of the experiment at day 46. The reason for a longer period of larval stages might be associated with the lower average temperature in this second trial compared to the first trial (Figure 5). In these experiments, all treatments were conducted within the range of recommended temperatures of $24^{\circ} \mathrm{C}-30^{\circ} \mathrm{C}$ (Zhang et al., 1998; Figueiredo \& Narciso, 2006; Calado et al., 2008, Calado et al., 2009). However, one exception was that the temperature in trial-2 before the installation of the heater at day 22 was lower $\left(27.63 \pm 0.16^{\circ} \mathrm{C}\right)$ than in trial-1 $(28.84 \pm$ $0.17^{\circ} \mathrm{C}$ ). According to Zhang et al. (1998) and Calado et al. (2008), a lower temperature will significantly prolong the duration of the larval stage of Lysmata spp.

In treatment 1D, three larvae still survived at day 46 with 3.33\%FASR. This survival rate was lower than in treatment $1 \mathrm{C}$ where none of the larvae had reached post-larval stage. However, it is hard to make a comparison between them since treatment 1D was conducted in a lower temperature range than treatment $1 \mathrm{C}$ which might affect the survival rate as the consequence of longer larval development at such high density. In treatment $1 \mathrm{E}$, there was only one larva survived at day 46 with $1.11 \%$ FASR. This result is better than treatments $1 \mathrm{~A}$ and $1 \mathrm{~B}$. On the contrary, the use of only Artemia in the diet (treatment 1F) has produced a lower survival rate at the early larval stage than the other treatments (1D and 1E). In spite of this, Artemia diets resulted in a better survival at the later larval stage. Several studies have also indicated that the use of Artemia as a diet for larvae of Lysmata spp. resulted in a better growth, development, and survival rate compared to other diets such as microalgae and rotifer (Zhang et al., 1998; Lin et al., 2002).

In trial-3, no larvae survived and reached postlarval stage (Figure 4). Although closely associated with L. vittata in size, appearance, color pattern, and habitat, L. intermedia has quite different characteristics. This species tends to be more vulnerable than other peppermint shrimp species, especially L. vittata. D'Acoz (2000) discovered that the geographical distribution of $\mathrm{L}$. intermedia is limited to tropical/subtropical region range from western Atlantic to the western Indian Ocean. On the other hand, L. vittata has a wider geographical distribution ranging from the eastern Atlantic to the western Pacific. It can be found along the eastern part of the African continent and Russian water of Sea of Japan to the northern coast of New Zealand (Marin et al., 2012). This wideranging distribution indicates that $L$. vittata is a more robust species than $L$. intermedia. Therefore, the culture and nursery of larvae L. intermedia are more difficult and complicated which probably responsible for the higher mortality rate of this species. In this trial, treatment 2B had a better average survival rate from the early stage until the end of the experiment. This result indicates that the use of copepod at an early stage was more effective to improve the survival rate of peppermint shrimp larvae rather than only fed them with Artemia as achieved in the previous experiment (treatment 1F). However, it is arguably difficult to make a comparison between both studied species as 
they have different responses to given feed and sensitivity to rearing environment.

\section{CONCLUSION}

The survival rates of $L$. vittata and $L$. intermedia larvae were low in all different combinations and feeding practices of live foods. However, each treatment showed a significant effect $(P<0.05)$ on the average survival rate of both species larvae. The use of copepod as live feed at an early larval stage and Artemia at a later stage is relatively more effective to improve the survival rate of peppermint shrimp larvae compared to the other treatments.

Both of the species are sensitive to low temperature which leads to a prolonged larval stage. A stable temperature at $28^{\circ} \mathrm{C}-29^{\circ} \mathrm{C}$ is advised in rearing Lysmatas spp. larvae to ensure the normal transformation to post-larval stage.

\section{ACKNOWLEDGEMENTS}

The authors sincerely thank Prof. Chaoshu Zeng and Fahad Alajmi at the College of Marine and Environmental Science, James Cook University, for their valuable support during the research.

\section{REFERENCES}

Baeza, J.A. (2008). Protandric simultaneous hermaphroditism in the shrimps Lysmata bahia and Lysmata intermedia. Invertebrate Biology, 127(2), 181-188.

Buskey, E.J., Coulter, C., \& Strom, S. (1993). Locomotory patterns of microzooplankton: potential effects on food selectivity of larval fish. Bulletin of Marine Science, 53(1), 29-43.

Calado, R., Dionísio, G., Bartilotti, C., Nunes, C., dos Santos, A., \&Dinis, M.T. (2008). Importance of light and larval morphology in starvation resistance and feeding ability of newly hatched marine ornamental shrimps Lysmata spp. (Decapoda: Hippolytidae). Aquaculture, 283(1-4), 56-63.

Calado, R. (2008). Marine ornamental shrimp: biology, aquaculture and conservation. John Wiley \& Sons.

Calado, R., Vitorino, A., Reis, A., Lopes da Silva, T., \& Dinis, M.T. (2009). Effect of different diets on larval production, quality and fatty acid profile of the marine ornamental shrimp Lysmata amboinensis (De Man, 1888), using wild larvae as a standard. Aquaculture Nutrition, 15(5), 484-491.

Cato, J.C. \& Brown, C.L. (Eds.). (2008). Marine ornamental species: collection, culture and conservation. John Wiley \& Sons.

Cunha, L., Mascaro, M., Chiapa, X., Costa, A., \& Simoes, N. (2008). Experimental studies on the effect of food in early larvae of the cleaner shrimp Lysmata amboinensis (De Mann, 1888) (Decapoda: Caridea: Hippolytidae). Aquaculture, 277(1), 117-123.

D'Acoz, C.D. (2000). Redescription of Lysmata intermedia (Kingsley, 1879) based on topotypical specimens, with remarks on Lysmata seticaudata (Risso, 1816) (Decapoda, Caridea, Hippolytidae). Crustaceana-International Journal of Crustacean Research, 73(6), 719-736.

Figueiredo, J. \& Narciso, L. (2006). Productivity improvement of Lysmata seticaudata (Risso, 1816) larval rearing protocol through modelling. Aquaculture, 261(4), 1249-1258.

Holt, G.J. (2003). Research on culturing the early life stages of marine ornamental fish. Marineornamental species-Collection, culture $\&$ conservation, p. 251254.

Le Vay, L., Jones, D.A., Puello-Cruz, A.C., Sangha, R.S., $\&$ Ngamphongsai, C. (2001). Digestion in relation to feeding strategies exhibited by crustacean larvae. Comparative Biochemistry and Physiology Part A: Molecular \& Integrative Physiology, 128(3), 621-628.

Lin, J., Zhang, D., \& Rhyne, A. (2002). Broodstock and larval nutrition of marine ornamental shrimp. Avances en NutriciónAcuicola VI, Cancún, México.

Marin, I.N., Korn, O.M., \& Kornienko, E.S. (2012). The caridean shrimp Lysmata vittata (Stimpson, 1860) (Decapoda: Hippolytidae): A new species for the fauna of Russia. Russian Journal of Marine Biology, 38(4), 359-363.

Marine Fish Direct. (2014). Marine Fish Invertebrates: Crabs/Shrimps/Lobsters. Retrieved 25 June 2014. http://marinefishdirect.com.au/invertebrates/crabsshrimp-lobsters.

Olivotto, I., Planas, M., Simões, N., Holt, G.J., Avella, M.A., \& Calado, R. (2011). Advances in breeding and rearing marine ornamentals. Journal of the World Aquaculture Society, 42(2), 135-166.

Palmtag, M.R. \& Holt, J. (2001). Captive rearing of fire shrimp (Lysmata debelius). Texas Sea Grant College Program.

Rhyne, A.L. \& Lin, J. (2004). Effects of different diets on larval development in a peppermint shrimp (Lysmata sp. (Risso)). Aquaculture Research, 35(12), 1179-1185.

Rocha, A.P.P. (2007). Experimental and commercial production of Lysmata seticaudata. Universidade de Lisboa, Faculdade de Ciências, Mestradoem Pescas e Aquacultura.

Simoes, F., Ribeiro, F., \& Jones, D.A. (2002). Feeding early larval stages of fire shrimp Lysmata debelius 
(Caridea, Hippolytidae). Aquaculture International, 10(5), 349-360.

Sokal, R.R. \& Rohlf, F.J. (1995). Biometry: The principles and practice of statistics in biological research. Edition 3. New York.

Støttrup, J.G. (2006). A review on the status and progress in rearing copepods for marine larviculture: Advantages and disadvantages among
Calanoid, Harpacticoid and Cyclopoid copepods. In International symposium, Monterrey, Nuevo León, México. (p. 970-694).

Zhang, D., Lin, J., \& Creswell, R.L. (1998). Effects of food and temperature on survival and development in the peppermint shrimp Lysmata wurdemanni. Journal of the World Aquaculture Society, 29(4), 471-476. 